\title{
KEAKTIFAN BERORGANISASI SEBAGAI FAKTOR PENDUKUNG PSYCHOLOGICALWELL-BEING BAGI LANJUT USIA
}

\author{
Kartinah, Nona Tunjung Satria Wati \\ Fakultas Ilmu Kesehatan Universitas Muhammadiyah Surakarta \\ e-mail : Kartinahrama@gmail.com
}

\begin{abstract}
The psychological problems in the elderly often occurs due to problems because the aging process that does not get good treatment, feeling helpless, not needed, the inability to accept reality is a condition that greatly affects the psychology of an elderly person. Another factor that also influences is psychosocial changes during the aging process which is a process of life transition and loss. The majority of life transitions occur because of experience of loss, which includes retirement, changes in financial conditions, changes in roles and relationships, changes in health and functional capabilities, and changes in social networks, and relocation. Common losses for the elderly usually revolve around losing a relationship due to the process of death. This study aims to determine the relationship of organizational activity with psychological well-being of elderly PWRI member of Western part Sambungmacan Sragen. This research is quantitative using descriptive correlative design and case control approach. The study population was 47 elderly members of the PWRI organization in Sambungmacan Sragen subdistrict. The sample of research is 47 elderly which is determined using total sampling technique. Research data collection using questionnaire instrument, while data analysis using Chi Square test. The results obtained Chi $i_{\text {obs }}$ for 10,219 ( $p$-value $\left.=0,000\right)$ so that $H_{0}$ rejected. The conclusion of the research that there was an association of activeness of association with psychological well-being of elderly PWRI member of Western part Sambungmacan district Sragen, that is the higher level of activeness, hence the level of prosperity of the elderly increases.
\end{abstract}

Keywords: elderly, activeness of organization, psychological well-being

\section{PENDAHULUAN}

Menurut WHO usia 60-75 tahun (elderly) disebut dengan lanjut usia. Seseorang yang berusia lebih dari 60 tahun disebut lanjut usia (UU No. 13 Tahun 1998). Pada usia tersebut, lansia akan mengalami perubahan dan penurunan fungsi pada tubuhnya, seperti penurunan fungsi kognitif, penurunan kondisi fisik, dan penurunan psikologis (Suardiman, 2011).

Terlebih untuk lansia yang memasuki masa pensiun tentunya mengalami banyak perubahan dalam kehidupannya (Marmer, 2011). Masa pensiun merupakan fase dewasa akhir yang ditandai menurunnya produktifitas seorang lansia agar beristirahat dalam bekerja atau rutinitas kerja (Trisusanti \& Satiningsih, 2012). 
Kesejahteraan psikologis merupakan suatu penerimaan diri terhadap kemampuan individunya, mampu berinteraksi dengan orang, bisa mengendalikan diri, mampu menghadapi tekanan sosial, dan mampu membuat individu berarti dalam hidupnya (Anggraeni \& Jannah, 2014). Ada beberapa faktor yang dapat mempengaruhi kesejahteraan psikologis individu antara lain jenis kelamin, kepribadiaan, usia, pengalaman keluarga, keterikatan dengan pekerjaan dan kehidupan lain, kesehatan, studi klinis (Ryff, 2014).

Dukungan sosial merupakan salah satu faktor yang mempengaruhi kesejahteraan individu. Dengan adanya perhatian, rasa nyaman, penghargaan merupakan bagian dari dukungan sosial. Hal tersebut didapatkan dari orang disekitar kita (Ramadhani, 2016).

Organisasi formal bagi pensiunan pegawai negeri sipil (PNS) di Indonesia disebut Persatuan Wredatama Republik Indonesia (PWRI). Lansia yang memasuki masa pensiun digabungkan dalam suatu organisasi yaitu PWRI. Keaktifan dalam organisasi PWRI mempunyai pengaruh besar dalam kesejahteraan psikologis karena di PWRI yaitu mampu mempererat persaudaraan sesama anggota PWRI, mandiri dengan kehidupan sosialnya, ekonomi, mampu mendekatkan diri kepada Allah SWT, meningkatkan kualitas hidup, menambah pengetahuan, membangun solidaritas sesama anggota PWRI.

Berdasarkan hasil survey lapangan yang dilakukan dengan wawancara kepada 7 responden lansia yang mengikuti organisasi PWRI di wilayah tersebut didapatkan hasil bahwa lansia yang aktif menyatakan senang mengikuti PWRI karena menambah pengalaman (penerimaan diri), saling silaturahmi antar anggota (hubungan positif dengan orang lain), bertukar pengalaman dengan sesama anggota (hubungan positif dengan orang lain), sangat bahagia apabila bertemu teman sesama anggota (penerimaan diri). Sedangkan lansia yang tidak aktif mengatakan malas mengikuti perkumpulan karena sibuk mengasuh cucu (penguasaan lingkungan), lansia berpikir sudah tua mau cari apa (tujuan dalam hidup), malas mondar-mandir (hubungan positif dengan orang lain. Sehingga untuk mengetahui perbedaan apakah psychological well-being lansia yang baik atau tidak dilihat dari kehadiran lansia.

\section{METODE PENELITIAN}

Penelitian ini merupakan penelitian kuantitatif menggunakan desain deskriptif korelasi dan pendekatan Cross Sectional. Populasi penelitian adalah 47 lanjut usia yang menjadi anggota organisasi PWRI di Kecamatan Sambungmacan Sragen. Sampel penelitian sebanyak 47 lansia yang ditentukan menggunakan teknik total sampling. Pengumpulan data penelitian menggunakan instrumen kuesioner, sedangkan analisis data menggunakan uji Chi Square. 


\section{HASIL DAN PEMBAHASAN}

Tabel .1. Karakteristik Responden

\begin{tabular}{lcc}
\hline Karakteristik & Frek & Pers (\%) \\
\hline Umur & 39 & 83 \\
a. $60-74$ tahun & 8 & 17 \\
b. $75-90$ tahun & 47 & 100 \\
Total & & \\
Jenis kelamin & 8 & 17 \\
a. Perempuan & 39 & 83 \\
b. Laki-laki & 47 & 100 \\
Total & & \\
Status pernikahan & 37 & 79 \\
a. Menikah & 10 & 21 \\
b. Janda/duda & 47 & 100 \\
Total & & \\
Pendidikan terakhir & 12 & 25 \\
a. SD & 14 & 30 \\
b. SMP & 8 & 17 \\
c. SMA & 13 & 28 \\
d. Diploma/sarjana & 47 & 100 \\
Total & & \\
\hline
\end{tabular}

Tabel.2. Distribusi Frekuensi Keaktifan Berorganisasi

\begin{tabular}{lcc}
\hline Keaktifan & Frek & Pers $(\%)$ \\
\hline Tidak aktif & 10 & 21 \\
Aktif & 37 & 79 \\
\hline Total & 47 & 100 \\
\hline
\end{tabular}

Tabel 3. Distribusi Frekuensi psychological well being

\begin{tabular}{lcc}
\hline Psychological Well-Being & Frek & Pers (\%) \\
\hline Rendah & 9 & 17 \\
Sedang & 35 & 74 \\
Tinggi & 4 & 8 \\
Total & 47 & 100 \\
\hline
\end{tabular}

Hasil uji Chi Square lanjutan diperoleh nilai $\chi^{2}$ hitung correction sebesar 9,781 dengan nilai signifikansi ( $p$-value) 0,002 seperti yang terlihat pada tabel 4 . Nilai signifikansi uji ( $p$-value) lebih rendah dari $0,05(0,002<0,05)$ sehingga keputusan uji adalah $\mathrm{H}_{0}$ ditolak, maka kesimpulan penelitian adalah hubungan keaktifan berorganisasi dengan psychological well-being lanjut usia anggota PWRI bagian Barat Kecamatan Sambungmacan Sragen. 
Tabel 4. Hubungan Keaktifan Berorganisasi dengan Psychological Well-Being Lanjut usia

\begin{tabular}{|c|c|c|c|c|c|c|c|}
\hline \multirow{3}{*}{ Keaktifan } & \multicolumn{6}{|c|}{ Psychological Well-Being } & \multirow{3}{*}{$\chi_{\text {hit }}^{2}=9,781$} \\
\hline & \multicolumn{2}{|c|}{ Rendah } & \multicolumn{2}{|c|}{ Tinggi } & \multicolumn{2}{|c|}{ Total } & \\
\hline & Frek & $\%$ & Frek & $\%$ & Frek & $\%$ & \\
\hline Tidak aktif & 5 & 50 & 5 & 50 & 10 & 100 & $\begin{array}{l}p \text {-value } \\
0,002\end{array}$ \\
\hline Aktif & 3 & 8 & 34 & 92 & 37 & 100 & \\
\hline Total & 8 & 17 & 39 & 83 & 47 & 100 & \\
\hline
\end{tabular}

Karakteristik umur responden sebagaimana ditampilkan pada tabel diatas menunjukkan distribusi umur responden sebagian besar adalah $60-74$ tahun (83\%) dan sisanya berusia 75 - 90 tahun. Karakteristik responden sebagian besar berusia 60-74 tahun atau menurut kategori umur WHO termasuk kategori Elderly.

Karakteristik jenis kelamin menunjukkan distribusi tertinggi adalah lakilaki (83\%) dan sisanya perempuan (17\%). Distribusi jenis kelamin responden jika ditinjau dari proporsi umum lansia menurut jenis kelamin adalah berbeda dengan data yang ada di masyarakat. Hal tersebut sebagaimana ditunjukkan pada hasil survey Statistik Penduduk Lanjut Usia Tahun 2014 yang mengemumukakan bahwa secara teoritis angka harapan hidup wanita lebih tinggi dari pada laki-laki sehingga keberadaan lansia perempuan akan lebih banyak dari pada lansia laki-laki.

Karakteristik status perkawinan responden menunjukkan distribusi tertinggi adalah menikah atau masih memiliki pasangan (79\%) dan sisanya adalah janda/duda (21\%). Keberadaan pasangan hidup berhubungan dengan adanya perhatian orang lain terhadap lansia. Perhatian dan dukungan keluarga membantu lansia dalam mengatasi permasalahan dalam masa tuanya.

Karakteristik tingkat pendidikan menunjukkan distribusi tertinggi adalah SMP (30\%) dan distribusi terendah adalah SMA (17\%). Tingkat pendidikan yang dimiliki responden membatasi kemampuan responden dalam memahami kondisi dirinya dan mencari pemecahan terhadap kondisi kesehatan dirinya. Tingkat pendidikan seseorang berpengaruh dalam memberikan respon terhadap sesuatu yang datang dari luar. Seseorang yang mempunyai tingkat pendidikan tinggi akan memberikan respon yang lebih rasional dalam menghadapi masalah sehingga dapat meminimalkan resiko depresi dan juga dalam motivasi kerjanya akan berpotensi dari pada mereka yang berpendidikan lebih rendah atau sedang (Notoatdmojo, 2010).

Distribusi tingkat keaktifan berorganisasi responden menunjukkan distribusi tertinggi adalah aktif (79\%) dan sisanya tidak aktif (21\%). Penelitian ini 
menunjukkan bahwa tingkat keaktifan berorganisaisi responden sebagian besar adalah aktif. Kondisi ini salah satunya disebabkan kondisi sosial ekonomi responden yang cukup baik yaitu sebagai pensiunan PNS yang tentunya secara ekonomi masih memiliki income atau pendapatan walaupun mereka sudah tidak bekerja. Hubungan tingkat sosial ekonomi dengan keaktifan menjalani kegiatan sosial pada lansia sebagaimana ditunjukkan dalam penelitian Pinto dan Neri (2017) yang menunjukkan bahwa faktor-faktor yang berhubungan dengan keaktifan lansia dalam mengikuti kegiatan sosial adalah faktor sosial ekonomi dan faktor dukungan sosial.

Distribusi tingkat kesejahteraan pada responden menunjukkan distribusi tertinggi adalah sedang (74\%), selanjutnya rendah (17\%) dan tinggi (8\%). Pada penelitian ini menunjukkan bahwa kesejahteraan psikologis responden sebagian besar adalah sedang. Beberapa faktor yang mendukung kesejahteraan tersebut adalah tingkat pendidikan dan status social. Tingkat pendidikan yang dimiliki oleh responden membantu lansia dalam memahami kondisi kehidupannya, serta tantangan-tantangan dalam kehidupan di masa tuanya baik dari segi fisik maupun psikologis.

Faktor lain adalah faktor sosial ekonomi responden. Tanaya dan Yasa (2014) mengemukakan bahwa beberapa factor yang berhubungan dengan kesejahteraan psikologis lansia adalah pemenuhan kebutuhan spiritual dan rekresi pada lansia.

Hasil uji Chi Square disimpulkan bahwa ada hubungan keaktifan berorganisasi dengan psychological well-being lanjut usia anggota PWRI bagian Barat Kecamatan Sambungmacan Sragen, yaitu semakin tinggi tingkat keaktifan, maka tingkat kesejahteraan lansia semakin meningkat.

Aktivitas berorganisasi yang dilakukan oleh responden berdampak pada masih adanya kegiatan-kegiatan yang bersifat kognitif oleh lansia, misalnya kegiatan organisasi PWRI bagian barat Kecamatan Sambungmacan Sragen dilakukan pertemuan setiap satu bulan sekali yaitu membahas tentang masalahmasalah PWRI seperti pergantian anggota, laporan tentang anggota yang sakit maupun keluar, kultum yang membahas tentang promosi kesehatan bagi lansia dan berbagi informasi tentang kartu kesehatan.Masih dilakukannya tindakan berpikir secara kognitif tersebut akan mendorong bertahannya daya ingat dan kemampuan kognitif pada lansia.

Hal tersebut sebagaimana ditunjukkan dalam penelitian $\mathrm{Fu}, \mathrm{Li}$ and $\mathrm{Mao}$ (2018) tentang hubungan aktivitas sosial dengan kemampuan kognitif pada lansia di China. Penelitian ini menyimpulkan bahwa terdapat hubungan yang signifikan aktivitas sosial dengan kemampuan kognitif lansia, dimana aktivitas sosial pada lansia dapat mendorong bertahannya kemampuan kognitif lansia sehingga membantu lansia dalam mempertahankan kualitas hidupnya. 


\section{KESIMPULAN}

Berdasarkan hasil penelitian dapat disimpulkan bahwa :

1. Karakteristik responden pada lanjut usia anggota PWRI bagian barat Kecamatan Sambungmacan Sragen, sebagian besar berusia 60 - 74 tahun, berjenis kelamin laki-laki, status pernikahan adalah menikah atau masih memiliki pasangan, dan tingkat pendidikan terakhir adalah SMP .

2. Tingkat keaktifan berorganisasi pada lanjut usia anggota PWRI bagian barat Kecamatan Sambungmacan Sragen sebagian besar adalah aktif.

3. Kesejahteraan psikologis (psychological well-being) lansia anggota PWRI bagian barat Kecamatan Sambungmacan Sragen sebagian besar adalah sedang.

4. Terdapat hubungan keaktifan berorganisasi dengan psychological well-being lanjut usia anggota PWRI bagian Barat Kecamatan Sambungmacan Sragen, yaitu semakin tinggi tingkat keaktifan, maka tingkat kesejahteraan lansia semakin meningkat.

Selanjutnya peneliti membuat rekomendasi sebagai berikut :

1. Bagi Lansia

Lansia diharapkan aktif dalam mengikuti kegiatan organisasi dan lansia diharapkan mampu menerima kondisi hidupnya.

2. Bagi Petugas Kesehatan

Petugas kesehatan dapat berperan aktif dalam memfasilitasi lansia yang aktif dalam kegiatan berorganisasi, misalnya dengan membentuk pengurus kegiatan olah raga bagi lansia dan sebagainya, sehingga tingkat keaktifan lansia dalam kegiatan bermasyarakat meningkat.

3. Bagi Peneliti Selanjutnya

Peneliti selanjutnya dapat menambahkan faktor-faktor lain yang berhubungan dengan kesejahteraan psikologis lansia, serta melakukan penelitian sejenis di wilayah perkotaan, sehingga hasil penelitian dapat lebih bersifat general.

4. Organisasi PWRI

Oganisasi PWRI dapat memberikan penyuluhan kepada lansia agar percaya diri dengan kondisinya, agar lansia mampu menerima dengan lingkungan yang baru baginya, dan lansia mampu saling memotivasi teman sesama anggota agar aktif berorganisasi.

\section{DAFTAR PUSTAKA}

Anggraeni, T. P., \& Jannah, M. (2014). Hubungan Antara Psychological WellBeing Dan Kepribadaian Hardiness Dengan Stress Pada Petugas Port Security. Character, Volume 3 No. 2.

Fu C, Li Z and Mao ZF (2018). Association between Social Activities and Cognitive Function among the Elderly in China: A Cross-Sectional Study. 
Article Research. International Journal of Environmental Research and Public

Marmer, W, P. (2011). Kejahteraan Psikologis (Psychological Well Being) Lansia. Surabaya : Fakultas Psikologi Universitas Airlangga.

Pinto JM and Neri AL. (2017). Factors related to low social participation in older adults: findings from the Fibra study, Brazil. Original Article. Cad. Saúde Colet., 2017, Rio de Janeiro, 25 (3): 286-293. Brazil: Universidade Estadual de Campinas (UNICAMP) - Campinas (SP).

Ryff, C. D. (2014). Psychological Well-Being Revisited: Advances in the Science and Practice Eudaimonia. Psychother Psychomsom 2014; 83:

Trisusanti, R., \& Satiningsih. (2012). Gambaran Psychological Well Being Pada Pria Pensiunan Pegawai Negeri Sipil Struktural Yang Menjadi Tulang Punggung Kleuarga. Jurnal Psikologi: Teori \& Terapan, Vol. 3, No. 1, Agustus 2012.

Undang-Undang No. 13 tahun (1998). Tentang Kesejahteraan Lanjut Usia.

WHO. (2016). Mental health and older adults. 